\title{
Transactions
}

Cite this: Dalton Trans., 2011, 40,7133

wWW.rsc.org/dalton

COMMUNICATION

\section{A novel Mn-containing conducting metallopolymer obtained by electropolymerization in aqueous solution of a tetranuclear oxo-bridged manganese complex}

\author{
Cibely S. Martin and Marcos F. S. Teixeira* \\ Received 22nd March 2011, Accepted 12th May 2011 \\ DOI: 10.1039/c1dt10487j
}

The $\left[\mathrm{Mn}_{4}{ }^{\mathrm{IV}} \mathrm{O}_{5}(\text { terpy })_{4}\left(\mathrm{H}_{2} \mathrm{O}\right)_{2}\right]^{6+}$ complex shows great potential for electrode modification by electropolymerization using cyclic voltammetry. The electropolymerization mechanism was based on the electron transfer between $\mathrm{d} x^{2}-y^{2}$ orbitals of the metallic center and $p \pi$ orbital of the ligand.

Polynuclear manganese [(ligand) $\mathrm{Mn}(\mathrm{IV})-\mathrm{O}_{2}-\mathrm{Mn}$ (III)(ligand) $]^{3+}$ complexes show a process of multiple step electron transfers, and can therefore be used as oxidation catalysts in various processes and their main advantages are stability, ease-of-use and a lower cost than catalysts requiring microorganisms. ${ }^{1-5}$ These complexes have received important contributions from synthetic model studies in order to biomimic the active centers of many enzymes in both homogeneous and heterogeneous catalysis. ${ }^{6}$ The electropolymerization technique has several advantages compared to chemical polymerization, such as the performance of deposition on the surface of conductor substrate, control of the amount of polymer formed, the possibility of formation of ultra-thin films and the need of small quantities of monomer. ${ }^{7}$ Furthermore, electrochemical studies can quickly provide information about the characteristics and properties of electropolymerized materials related to charge transfer and catalytic activities. ${ }^{8}$ Reports on electropolymerization in aqueous inorganic complexes containing ligands such as terpyridine and containing manganese ion as central metal have not been reported in the literature, there are only reports of electropolymerization containing similar ligands and/or manganese ion centers, but all carried out in organic solvents. ${ }^{9,10}$

In this work the electropolymerization mechanism of $\left[\mathrm{Mn}_{4}{ }^{\mathrm{IV}} \mathrm{O}_{5}\right.$ (terpy) $\left.{ }_{4}\left(\mathrm{H}_{2} \mathrm{O}\right)_{2}\right]\left(\mathrm{ClO}_{4}\right)_{6}$ (oxo-bridged manganese tetranuclear complex) on a glassy carbon (GC) electrode surface in aqueous solution is described.

The $\left[\mathrm{Mn}_{4}{ }^{\mathrm{IV}} \mathrm{O}_{5}(\text { terpy })_{4}\left(\mathrm{H}_{2} \mathrm{O}\right)_{2}\right]\left(\mathrm{ClO}_{4}\right)_{6} \cdot 3 \mathrm{H}_{2} \mathrm{O}$ complex was synthesized according to the literature procedure. ${ }^{9} 2,2^{\prime}: 6,2^{\prime \prime}$ Terpyridine (Aldrich) (0.63 mmol) was dissolved in $\mathrm{CH}_{3} \mathrm{CN}$, and then a solution of $\mathrm{MnNO}_{3} \cdot 4 \mathrm{H}_{2} \mathrm{O}$ (Aldrich) $(0.60 \mathrm{mmol})$ in $\mathrm{H}_{2} \mathrm{O}$ was added. After all reactants were dissolved, the yellow

Department of Physics, Chemistry and Biology - Faculty of Science and Technology - University of State of Sao Paulo (Unesp), Presidente Prudente, SP-Brazil. E-mail: funcao@fct.unesp.br; Fax: 55-18-32215682; Tel: 55-18-32295749 mixture was stirred in an ice bath for $10 \mathrm{~min}$. Then the Oxone ${ }^{\circledR}$ (0.90 mmol, Aldrich) in water was added dropwise to the mixture, which turned deep red in about $15 \mathrm{~min}$. A large excess of solid $\mathrm{NaClO}_{4}$ was added to the mixture, and the $\mathrm{pH}$ of the solution was adjusted to 2 by addition of concentrated $\mathrm{HNO}_{3}$. This mixture was transferred to a series of small test tubes and allowed to slowly evaporate in the dark. As a result, needle-like blackred crystals of $\left[\mathrm{Mn}_{4}{ }^{\mathrm{IV}} \mathrm{O}_{5}(\text { terpy })_{4}\left(\mathrm{H}_{2} \mathrm{O}\right)_{2}\right]\left(\mathrm{ClO}_{4}\right)_{6}$ and orange-red crystals of $\left[\mathrm{Mn}^{\mathrm{II}}(\text { terpy })_{2}\right]\left(\mathrm{ClO}_{4}\right)_{2}$ were formed concomitantly in approximately two weeks. The needles were carefully separated and washed first with several drops of $\mathrm{HNO}_{3}$ solution $(\mathrm{pH}=2)$ and then with $3 \mathrm{~mL}$ of diethyl ether. The final product was left in desiccators for complete evaporation of the solvent.

The polymeric film was obtained by potential scans on a glassy carbon electrode surface from -0.2 to $1.2 \mathrm{~V} v s$. SCE potential range in the presence of $1 \mathrm{mmol} \mathrm{L}^{-1}$ of the complex in $0.5 \mathrm{~mol}$ $\mathrm{L}^{-1} \mathrm{NaNO}_{3}$ with $15 \mathrm{mV} \mathrm{s}^{-1}$ scan rate. The modified electrode was washed with deionized water. After the film was formed by electropolymerization, the electrochemical behavior of the modified electrode was carried out in a $0.5 \mathrm{~mol} \mathrm{~L}^{-1} \mathrm{NaNO}_{3}$ solution from 0.25 to $1.2 \mathrm{~V} v s$. SCE potential range with $25 \mathrm{mV} \mathrm{s}^{-1}$ scan rate. The effect of the scan rate (from 5 to $200 \mathrm{mV} \mathrm{s}^{-1}$ ) in a $0.5 \mathrm{~mol} \mathrm{~L}^{-1}$ $\mathrm{NaNO}_{3}$ solution was also performed under the same conditions. The $\mathrm{pH}$ dependence of the film oxidation at the electrode surface was realized by cyclic voltammetry in acetate buffer. A study at a ITO/glass electrode was also performed to measure the behavior of film formation in more detail.

In the cyclic voltammograms (Fig. 1) a consecutively increase of the current for both anodic $(0.92 \mathrm{~V})$ and cathodic $(0.80 \mathrm{~V})$ peaks is observed, demonstrating that the Mn-containing conducting metallopolymer is continuously deposited on the electrode surface with increasing numbers of potential scans. The electropolymerization voltammograms are similar to the voltammograms for the complex in solution, therefore, they confirm that the redox process observed in the electropolymerization stage is assigned to the redox couple $\mathrm{Mn}^{\mathrm{IV}} / \mathrm{Mn}^{\mathrm{III}}$ present in the metallic center of the complex.

After the electropolymerization stage, the modified electrode was subjected to cyclic scanning in a $0.5 \mathrm{~mol} \mathrm{~L}^{-1} \mathrm{NaNO}_{3}$ solution in the absence of the complex in the solution from 0.25 to $1.2 \mathrm{~V}$ vs. SCE range potential at $25 \mathrm{mV} \mathrm{s}^{-1}$. The obtained cyclic voltammogram (Fig. 2) showed one redox couple with an 


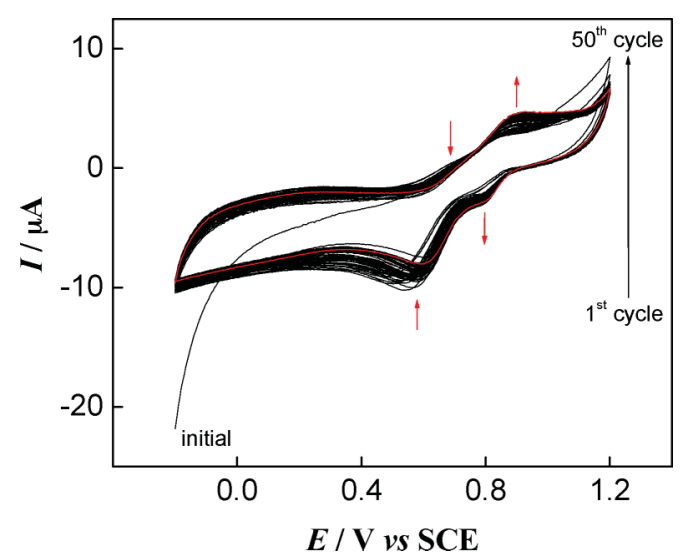

Fig. 1 Cyclic voltammograms (50 cycles) for the electropolymerization of the oxo-bridged manganese tetranuclear complex $\left(1.0 \mathrm{mmol} \mathrm{L}^{-1}\right)$ in $0.5 \mathrm{~mol} \mathrm{~L}^{-1} \mathrm{NaNO}_{3}$ on a glassy carbon electrode. $v=15 \mathrm{mV} \mathrm{s}^{-1}$.

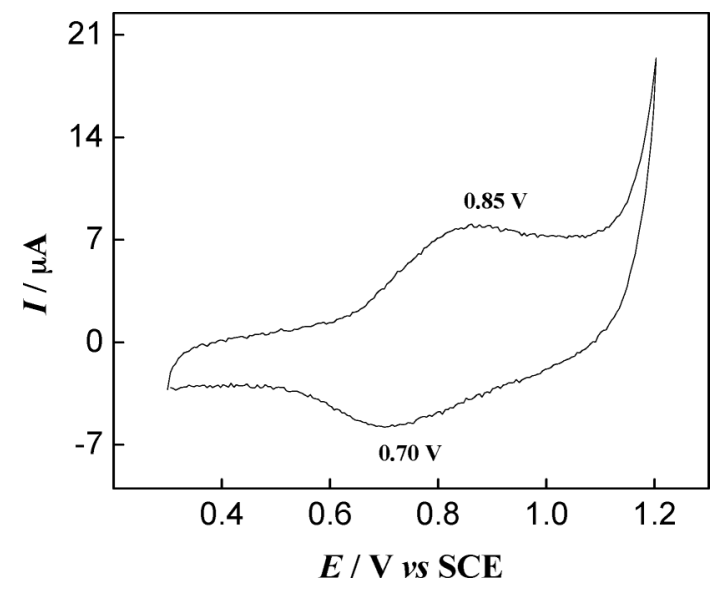

Fig. 2 Cyclic voltammogram obtained for the electrode modified with the polymeric film in $0.5 \mathrm{~mol} \mathrm{~L}^{-1} \mathrm{NaNO}_{3}$ solution. $v=25 \mathrm{mV} \mathrm{s}^{-1}$.

anodic peak at $0.85 \mathrm{~V}$ and a cathodic peak at $0.70 \mathrm{~V}$ vs. SCE, these peaks are assigned to $\mathrm{Mn}^{\mathrm{IV}} / \mathrm{Mn}^{\mathrm{III}}$ present in the polymer deposited on the electrode surface. The presence of only one redox couple confirms the formation of the homogeneous film, where all manganese centers exhibit a symmetry in the molecular structure with the same oxidation state. The increase of peak current values for the modified electrode in aqueous solution after the electropolymerization process can be assigned to film homogeneous formation on the electrode surface. A shift to more positive potential regions was also observed, which may be assigned to the stability of the film formed due to multielectronic transfer provided by $\pi$ electrons of the aromatic rings present in the terpyridine ligand. The interaction of the metallic complex on the electrode surface can be observed for pretreated glassy carbon electrodes, edge plane pyrolytic graphite electrodes and glassy carbon electrodes due to adsorbed quinines, which shows interactions with the metallic centers of the complex. ${ }^{11,12}$ Recently, we have studied the electropolymerization of the complex onto a platinum electrode in the same experimental conditions. No effects on the activity of the metallic cation were observed for polymer formation.
The electropolymerization mechanism is strongly influenced by the ligand field. For the oxo-bridged manganese tetranuclear complex, the strong-field ligand causes a loss of degeneracy of the $d$ orbitals of the octahedral crystal field of the complex containing $\mathrm{Mn}^{\mathrm{IV}}$ centers. The out-of-plane orbitals, $d x z, d y z$ and $d z^{2}$, have an interaction with $\pi^{*}$ orbitals of the nitrogen atoms present on the terpyridine ligands, featuring a bond $d \pi-\pi^{*}$, while the orbitals in the $x y$ plane interact strongly with the $p \pi$ orbital of the oxygen, featuring a bond of di- $\mu$-oxo type. The orbitals overlapping of the di- $\mu$-oxo bond is characterized by the $p \pi-d \pi$ bond. ${ }^{13}$ The lowest unoccupied molecular orbital (LUMO) $d x^{2}-y^{2}$ is stabilized by $p \pi$ electron donors of the aqua ligand. Therefore, the $d \pi^{*}(\mathrm{LUMO})$ orbital is totally overlapped by the $p \pi$ orbitals of the $\mathrm{O}_{\text {aqua }}$. As a result, the gain and loss of electrons (from the electrode Fermi levels) occur at the $d \pi^{*}$ level making the Metal$\mathrm{OH}_{2}$ bond polarized. Even doing the direct bond with the metal, the aqua ligand continues to make hydrogen bonds with the lattice by increasing the stability of the complex. ${ }^{14}$ Due to the great potential of electron donors of the aqua ligand, a change of the hybridization of $\mathrm{O}_{\text {aqua }}$ atom ${ }^{13}$ occurs during the oxidation process, where the instability of one electron pair of the oxygen atom reacts with free water molecules releasing protons and consequently one new $\mu$-oxo bond is formed between two units of the complex at high potential values. The mechanism involving the water oxidation at high potential values with subsequent formation of $\mu$-oxo bridged is represented in Scheme 1.

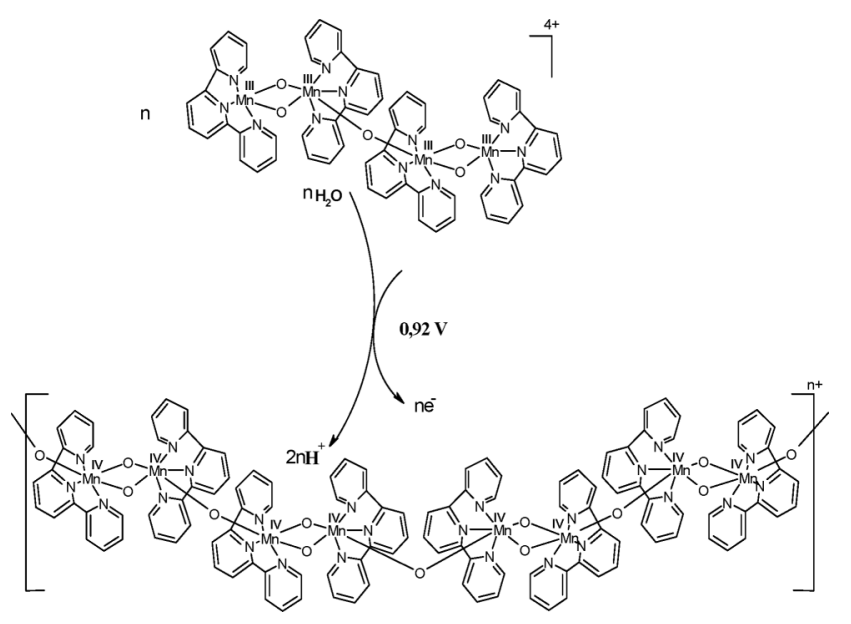

Scheme 1 Representation of the electropolymerization mechanism for the oxo-bridged manganese tetranuclear complex.

In each electropolymerization cycle, a decrease of the peak current values of the reduction process at $0.60 \mathrm{~V} v s$. SCE (see Fig. 1) is observed, which can be assigned to rearrangement of the bonds coupled during oxidation of $\mathrm{Mn}^{\mathrm{III}}$ (high spin) to $\mathrm{Mn}^{\mathrm{IV}}$. The structural rearrangements are relatively fast at the time that the potential scan rate is applied. ${ }^{15}$ Due to rearrangement of both $d x^{2}-y^{2}$ and $p \pi$ orbitals for the formation of a new $\mu$-oxo bridged, a higher stability of the polymer-complex containing $\mathrm{Mn}^{\mathrm{IV}}$ centers is proportioned. The redox potential for the oxo-bridged manganese tetranuclear complex in solution is similar to that observed for the polymeric film, indicating that the formation of this inorganic polymer occurs by the bond between the subunits of the complex, 
which can be in equilibrium with the subunits of the oxobridged manganese binuclear complex, as shown in the equation below:

$$
2\left[\mathrm{Mn}_{2}{ }^{\mathrm{IV}} \mathrm{O}_{2}(\text { terpy })_{2}\left(\mathrm{H}_{2} \mathrm{O}\right)_{2}\right]^{4+} \underset{+\mathrm{H}_{2} \mathrm{O},+2 \mathrm{H}^{+}}{\stackrel{-\mathrm{H}_{2} \mathrm{O}-2 \mathrm{H}^{+}}{\rightleftharpoons}}\left[\mathrm{Mn}_{4}{ }^{\mathrm{VV}} \mathrm{O}_{5}(\text { terpy })_{4}\left(\mathrm{H}_{2} \mathrm{O}\right)_{2}\right]^{6+}
$$

The presence of $\left[\mathrm{Mn}_{2}{ }^{\mathrm{IV}} \mathrm{O}_{2}(\text { terpy })_{2}\left(\mathrm{H}_{2} \mathrm{O}\right)_{2}\right]^{4+}$ (oxo-bridged manganese binuclear complex) in solution can be confirmed by both decrease of current values at $0.60 \mathrm{~V} v s$. SCE assigned to oxobridged manganese binuclear complex and increase of current values at $0.92\left(E_{\mathrm{pa}}\right)$ and $0.80\left(E_{\mathrm{pc}}\right) v s$. SCE assigned to the oxobridged manganese tetranuclear complex. The formation of a new bond is aided by the terpyridine ligand, because it keeps the manganese ions in high spin $\left(d^{4}-\mathrm{Mn}^{\mathrm{III}}\right)$ and the oxidation of $\mathrm{Mn}^{\mathrm{III}}$ to $\mathrm{Mn}^{\mathrm{IV}}$ occurs more efficiently for polymer formation. Comparing with other ligands like bipyridine and phenanthroline, the terpyridine complex shows a faster kinetic of dimerization, in which only one $\mu$-oxo bridged is necessary for the interconversion process. ${ }^{16}$

The redox potential for the oxo-bridged manganese tetranuclear complex in solution is similar to that observed for the polymeric film, indicating that the formation of this inorganic polymer occurs by bonding of the subunits of the complex. The influence of scan rate and potential cycle numbers on the electropolymerization process by cyclic voltammetry was realized. The optimal conditions were observed for 50 potential cycles at $15 \mathrm{mV} \mathrm{s}^{-1}$, in which it was shown a surface coverage of $5.26 \times 10^{-9} \mathrm{~mol} \mathrm{~cm}^{-2}$. Above 80 cycles, no significant increase of current was observed which may be due to saturation of the electrode surface. For scan rate higher than $25 \mathrm{mV} \mathrm{s}^{-1}$ only one redox process is observed at the electropolymerization stage, this behavior can be assigned to slow dimerization of the oxo-bridged manganese binuclear complex. Hence, a smaller efficiency for electropolymerization is observed by surface coverage values decrease.

To determine the role of protons in the electrochemical behavior of the film formed at the electrode surface, a cyclic voltammetry study was performed in acetate buffer $(\mathrm{pH} 2.8-8.8)$. The results indicate that the film oxidation potential varies with $\mathrm{pH}$, where the charge accumulated by oxidation of the metal centers is balanced by the loss of a proton. ${ }^{17,18}$ The fact that the film shows $\mathrm{pH}$ dependence can be assigned to the site of deprotonation present in the complexes with a terminal water ligand. ${ }^{19}$ These measurements have allowed us to elucidate not only the proton-coupled oxidation of the film at the electrode surface but also helped us to clarify the mechanism of water oxidation in both formation and stability of the film. A slope of $120 \mathrm{mV} \mathrm{pH}^{-1}$ for $\mathrm{pH} v$ s. redox potential $\left(E_{p / 2}\right)$ confirm that the electron transfer process is multielectronic, which may be assigned to the formation of a homogeneous film containing $\mathrm{Mn}^{\mathrm{IV}}$ centers.

A structural study of Mn-containing conducting metallopolymer was realized at a ITO electrode surface and evaluated by UV-Vis spectroscopy. The electropolymerization process was performed in the same conditions used for the glassy carbon electrode. The visible spectrum of the Mn-containing conducting metallopolymer onto the ITO surface (Fig. 3) shows three absorbance bands, which can be assigned to $\mathrm{Mn}^{\mathrm{IV}} d-d$ and $\mathrm{Mn}^{\mathrm{IV}}-$ Ligand transitions. ${ }^{19}$ The band at $350 \mathrm{~nm}$ assigned to $d \pi-\pi^{*}$ transitions is intense because they are both spin-allowed and

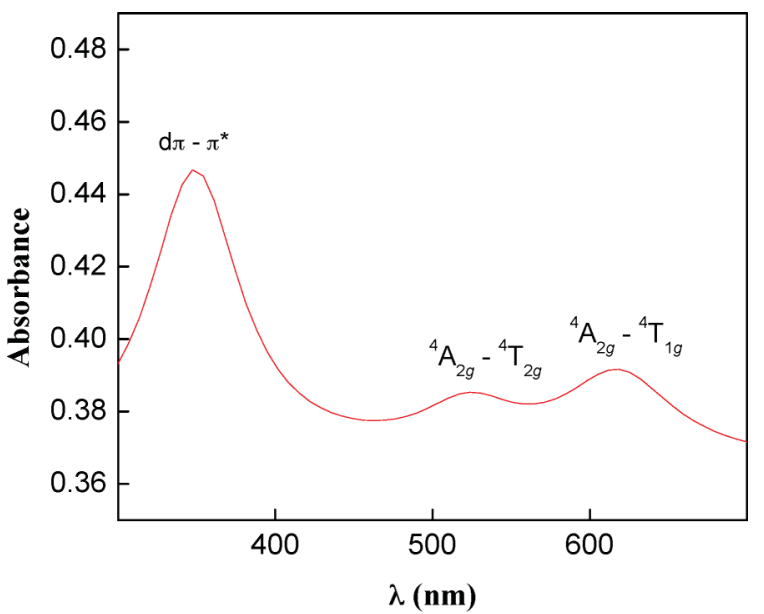

Fig. 3 Visible spectrum obtained for a Mn-containing conducting metallopolymer formed onto the ITO surface.

Laporte-allowed, that occurs by donation of electrons from filled $d$ orbitals of the metal to empty $\pi$ antibonding orbitals of the ligand. The bands of lower intensity (shoulders) observed in 523 and $618 \mathrm{~nm}$ can be assigned to $\mathrm{Mn}^{\mathrm{IV}} d-d$ transitions. The lower intensity occurs due to spin-forbidden $(\Delta S \neq 0)$ and Laporteforbidden $(\Delta l \neq 1)$ transitions present in metals of configuration $d^{3}$, and for $\mathrm{Mn}^{\text {IV }}$ the shoulders observed can be assigned to ${ }^{4} \mathrm{~A}_{2 g} \rightarrow{ }^{4} \mathrm{~T}_{2 g}$ and ${ }^{4} \mathrm{~A}_{2 g} \rightarrow{ }^{4} \mathrm{~T}_{1 g}$, respectively. This effect is observed due to a great molecular organization of the film formed on the electrode surface.

The best electropolymerization conditions were observed at low scan rate and 50 potential cycles, which can be assigned to slow dimerization and consequent formation of polymeric film on the electrode surface. The polymer formation of the complex containing a tridentate ligand with high electronic density is more favored. Another important factor for electropolymerization is the requirement of free water molecules, this way the aqueous medium is highly favorable. The synthesized film onto the electrode surface can be applied for electrocatalysed reactions and for the development of chemical sensors.

\section{Notes and references}

1 T. Tzedakis, Electrochim. Acta, 2000, 46, 99.

2 A. Gref, G. Balavoine and H. Riviere, New J. Chem., 1984, 8, 615.

3 K. Wieghardt, U. Bossek, B. Nuber, J. Weiss, J. Bonvoisin, M. Corbella, S. E. Vitols and J. J. Girerd, J. Am. Chem. Soc., 1988, 110, 7398.

4 R. Bilewicz and E. Muszalska, J. Electroanal. Chem., 1991, 300, 147.

5 R. Manchanda, H. H. Thorp, G. W. Brudvig and R. H. Crabtree, Inorg. Chem., 1992, 31, 4040.

6 E. J. Larson and V. L. Pecoraro, In: Manganese Redox Enzymes, VCH Publishers, New York, 1992.

7 G. Nie, L. Zhou, Y. Zhang and J. Xu, J. Appl. Polym. Sci., 2010, 117, 793.

8 L. B. Kenneth and S. B. Gray, Int. J. Chem., 2010, $2,3$.

9 H. Chen, J. W. Faller, R. H. Crabtree and G. W. Brudvig, J. Am. Chem. Soc., 2004, 126, 7345 .

10 J. Hjelm, R. W. Handel, A. Hagfeldt, E. C. Constable, C. E. Housecroff and R. J. Foster, Inorg. Chem., 2005, 44, 1073.

11 C. M. Che, K. Y. Wong and F. C. Anson, J. Electroanal. Chem., 1987, 226, 211. 
12 G. E. Cabaniss, A. A. Diamantis, W. R. Murphy, R. W. Linton and T. J. Meyer, J. Am. Chem. Soc., 1985, 107, 1845.

13 T. J. Meyer and M. H. V. Huynh, Inorg. Chem., 2003, 42, 8140.

14 K. R. Reddy, M. V. Rajasekharan, N. Arulsamy and D. J. Hodgson, Inorg. Chem., 1996, 35, 2283.

15 S. R. Cooper, G. C. Dismukes, M. P. Klein and M. Calvin, J. Am. Chem. Soc., 1978, 100, 7248.
16 C. Baffert, S. Romain, A. Richardot, J. C. Leprête, B. Lefebvre, A. Deronzier and M. N. Collomb, J. Am. Chem. Soc., 2005, 127, 13694.

17 M. J. Baldwin and V. L. Pecoraro, J. Am. Chem. Soc., 1996, 118, 11325.

18 M. T. Caudle and V. L. Percoraro, J. Am. Chem. Soc., 1997, 119, 3415.

19 C. W. Cady, K. E. Shinopoulos, R. H. Crabtree and G. W. Brudvig, Dalton Trans., 2010, 39, 3985. 